Article

\title{
Novel Technique for Coating of Fine Particles Using Fluidized Bed and Aerosol Atomizer
}

\author{
Rongyi Zhang *, Torsten Hoffmann and Evangelos Tsotsas $\mathbb{D}$ \\ Thermal Process Engineering, Otto von Guericke University, Universitäts Platz 2, 39106 Magdeburg, Germany; \\ torsten.hoffmann@ovgu.de (T.H.); evangelos.tsotsas@ovgu.de (E.T.) \\ * Correspondence: rongyi.zhang@ovgu.de
}

Received: 29 October 2020; Accepted: 19 November 2020; Published: 24 November 2020

\begin{abstract}
Fine particles are widely used in many industrial fields, and there are many techniques applied for these particles, like electroplating, and chemical and physical vapor deposition. However, in the food and pharmaceutical industries, most coating processes conducted with fluidized bed use core particles with a diameter larger than $200 \mu \mathrm{m}$, otherwise agglomerates are formed. This study contributes to the development of a new coating process for fine particles with diameters of around $50 \mu \mathrm{m}$. The innovation lies in the combined use of a Wurster fluidized bed and a novel aerosol atomizer. The feasibility of the operation is based on the application of the aerosol atomizer, which generates droplets smaller than $1 \mu \mathrm{m}$ in diameter. A series of experiments with different coating solutions and glass beads in a $150 \mathrm{~mm}$ fluidized bed fed with droplet aerosol supplied from the cone chamber bottom is presented. The quality of the coating product is analyzed by scanning electron microscopy and CAMSIZER ${ }^{\circledR}$. In this way, the influence of different conditions and core material properties on the product quality were determined. Experimental results showed the coating layer quality getting worse as coating solution viscosity became lower, meanwhile moderate process temperature was found to enhance coating layer formation and quality of that. It was also observed that lower aerosol feed rates help improve the yield of the process.
\end{abstract}

Keywords: coating; aerosol generator; fluidized bed; fine particles

\section{Introduction}

The coating of particulate materials is an important process for various industries, including the chemical, food and pharmaceutical industries [1]. Coating is frequently used for protective or functional purpose [2,3]. Additionally, the visual properties of the particles can also be changed [4]. Therefore, through coating processes, various properties can be achieved, such as stabilization of active substances, enhanced mechanical properties, masking of taste and odor, improved optical appearance, and defined drug release profile in the human body [5]. Among different particulate materials, fine particles have come to be of major interest lately. Many industrial sectors are expected to find applications and take advantage of the new functionalities and many desirable properties attributed to ultrafine particles, e.g., their use as drug delivery carriers [6].

Application of the coating layer to the surface of a particle is a complex process [5]. Typically, a suspension or solution is sprayed onto the particles, after that, every single particle is wrapped by the liquid film. New solid layers are formed after the liquid in the film has evaporated, which results in coating of the particles. Specifically, depending on the apparatus used and the coating material conditions, the process may comprise the following steps: droplet formation, wetting, spreading, evaporation, and drying [7].

Fluidization is one of the most important techniques in the particle formation process because it possesses the advantages of high heat and mass transfer rates, good mixing and homogeneity. With the 
increasing progress of experimental methods and mathematical models in recent years, the spray fluidized bed coating of particulate materials is becoming an established industrial process $[8,9]$. Despite this, fluidized bed coating without severe agglomeration is typically limited to particle sizes larger than $100 \mu \mathrm{m}$ [5]. On the one hand, the reason for this is that fine powders fluidize poorly due to their strong interparticle cohesive forces, exhibiting channeling, lifting as a plug and forming "rat holes" when aerated [10]. On the other hand, when using ordinary two-fluid nozzles, the spray is composed of droplets with an average diameter of $40 \mu \mathrm{m}$ or more [11], which can be considered to be large droplets relative to the particle size. Hence, an over-wetted particle surface will result in strong cohesive forces of liquid bridges that hold particles together after the particles collide with each other during the drying process. These are converted to solid bridges upon drying, fixing the structure of agglomerates that will not break in the subsequent steps [12].

To overcome these issues, conventional methods can be optimized by improving the particles or modifying the fluidized bed. Thereby, powders can be granulated with larger particles in order to enhance the fluidization, drying and coating process in the fluidized bed [13]. Otherwise, fluidization can also be assisted by a variety of mechanisms such as vibration, mechanical agitation, sound and magnetic force to improve the flowability of cohesive particles $[6,14,15]$. Such approaches are effective in the formation of coating layers, but they also have the disadvantage of limited application ranges. When granulating the fine particles with coarse ones, the high concentration of easily fluidized material will finally influence the product purity. Additionally, most assistance techniques require complicated modifications to the traditional fluidized bed configuration that might demand large additional costs.

Recently, several researchers have tried to coat fine particles by using different apparatuses for under various operating conditions. For instance, a Wurster fluidized bed was used by Ichikawa et al. [16] along with $12 \mu \mathrm{m}$ cornstarch as the core particles and composite of polymers as the coating material. The corresponding product only contained $3 \mathrm{wt} . \%$ agglomerates. However, there were still some ineluctable problems when using this method: for example, sufficiently prolonged release properties could not be obtained. Watano et al. $[6,17]$ tried the rotating fluidized bed using fine cornstarch particles. In this case, the cohesive cornstarch particles behaved like particles that could be well fluidized because the centrifugal forces on increased the apparent particle weight. This led to cornstarch being successfully coated nearly without agglomeration. However, this method required a complex apparatus and a significant amount of energy caused by the huge pressure drop through the particles. Chen et al. $[18,19]$ proposed a way in which core materials were pretreated by deposition of nano-particles on the surface of fine particles. The addition of a nano-particle surface coating reduces the cohesive behavior so that fine particles can fluidize in a conventional fluidized bed and good quality coating product may be obtained. Nevertheless, the pretreatment process was inefficient and time-consuming, which is a big drawback in large-scale industrial production. The recent work of Hampel et al. [20] developed a new method that combined two particle formulation processes: spray drying and coating. The idea was to spray fine particles to be coated together with coating solution means of a two-fluid nozzle, aiming at the generation of droplets with only one contained particle at the nozzle outlet. After evaporation of the water in such a droplet, a thin solid film is built on the particle surface. This innovative, low-cost and easy-to-implement method could avoid the occurrence of agglomeration to a certain extent, but partly coated or even uncoated products appeared under certain process conditions.

As indicated by the previous experiments conducted in a fluidized bed, a difficulty lies in successfully fluidizing the original fine particles. Previous research by Ichikawa et al. demonstrated that the bottom-spray Wurster bed is an effective way of improving the fluidization behavior of cohesive fine particles [16]. However, as mentioned earlier, large spray droplets lead to the formation of agglomerates, so that individual coating of fine particles still be a challenge and this work is focus on the topic. 
A radical change from conventional spray to aerosol for coating process in fluidized bed is presented in this work. The aerosol, generated by a recently developed method [21,22], was supplied into the chamber of a Wurster fluidized bed from the bottom. It was recently shown that ultrathin coating can be easily produced on large particles in a traditional fluidized bed by such an aerosol [23]. Here, the coating of fine particles was in focus. The working hypothesis was that aerosol with diameters 10-100 times smaller than regular sprays would be more suitable for fine particles and enable uniform coating layers and without the excessive agglomeration that traditional spray fluidized bed particle coating systems show.

In this work, investigations will be presented on the effect that operating conditions such as core material size, air temperature, coating material concentration and the presence of the additive in coating solution have on efficacy of the presented process to produce coated fine particles. Finally, the influence of operating conditions on the resulting product quality will be described and discussed; the strengths and weaknesses of the novel aerosol coating process to its conventional counterpart will be summarized.

\section{Experimental}

\subsection{Aerosol Generation}

A simple and reliable technique for the generation of aerosol droplets was recently developed and investigated by Mezhericher [21,22]. Compared to traditional liquid atomization technologies [24], this method is based on shear-driven disintegration by gas jets of thin liquid films formed by gas bubbles on a liquid surface. The main part of the device is an elastic rubber tube which is perforated with ostioles along the tube at several axial positions. The tube is horizontally placed and partially submerged in a vessel filled with coating solution: the lower part of the tube is immersed in the liquid, and the upper portion of the tube is exposed to the air, see Figure 1a. The air inlet tube is connected to compressed air, and the stable compressed air is discharged through the perforated ostioles. Many small bubbles which are caused by the compressed air through the lower part of the tube, then come up to the liquid surface and create a foam of thin spherical liquid films near the upper part of the tube. Soon afterwards, the air discharged through the upper ostioles breaks and disintegrates these foams into aerosol droplets, as schematically illustrated in Figure 1b. In this study, a self-made aerosol generator developed based on this principle was used in the experiments.

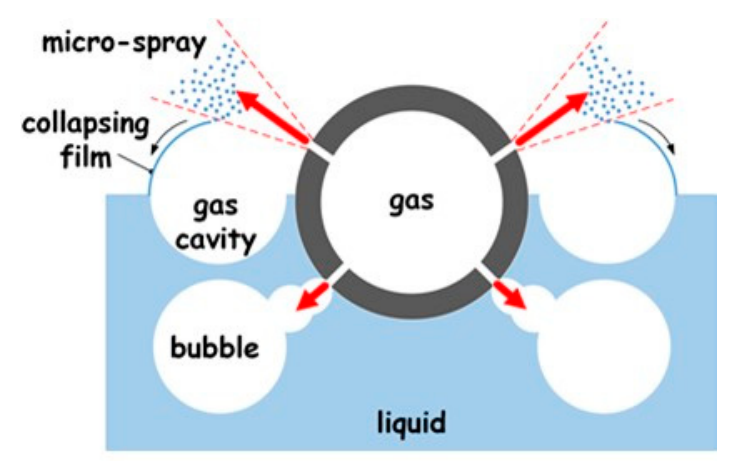

(a)

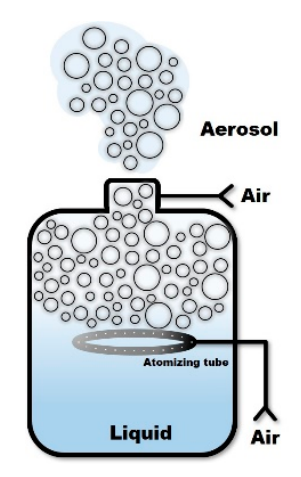

(b)

Figure 1. (a) Simultaneous production of bubbles, gas jets and micro-sprays of fine droplets in a cross-section of the atomizing tube [25]; (b) schematic of novel aerosol generator.

The central part of the device was a $220 \mathrm{~mm}$ polyvinyl chloride tube of $12 \mathrm{~mm}$ outer diameter. The $1.5 \mathrm{~mm}$ walls of the tube were perforated with $0.6 \mathrm{~mm}$ ostioles along the tube circumference at four axial positions ( 38 orifices per line, 144 in total). The tube was horizontally oriented and partially submerged into a plastic vessel filled with tap water or coating solution. This vessel had dimensions 
of $16.5 \mathrm{~cm}$ (diameter) $\times 18.5 \mathrm{~cm}$ (height) and a circular outlet of $4 \mathrm{~cm}$ at its upper horizontal wall. A flexible PVC tube with a length of $165 \mathrm{~cm}$ connected the outlet of the container and the fluidized bed, so that droplets and gas could flow out horizontally from the container.

Droplet size distributions produced by the aerosol generator were characterized separately by means of a laser diffraction system (Particle Analyzer LA-960, Retsch Technologies, Haan, Germany) Measurement results obtained for different coating solutions are shown in Figure 2a. To ensure a constant liquid level, solution was pumped to the aerosol atomizer through a peristaltic pump from another container. Then, the flow rate of the droplets was calculated by measuring the amount of liquid left in the storage tank and the corresponding time interval. Figure $2 b$ indicates the flow rate of the aerosol generator under different operating conditions. The volumetric size distributions of Figure $2 \mathrm{a}$ demonstrate that aerosol droplet diameters range from $0.1 \mu \mathrm{m}$ to $10 \mu \mathrm{m}$, and the mean droplet size of the aerosol used in the experiments is smaller than $1 \mu \mathrm{m}$. Figure $2 \mathrm{~b}$ shows that the liquid flow rate of the generated aerosol increases with atomizing pressure.

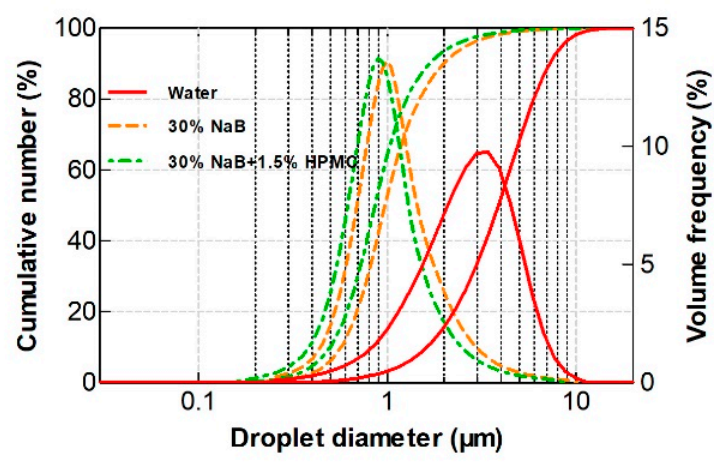

(a)

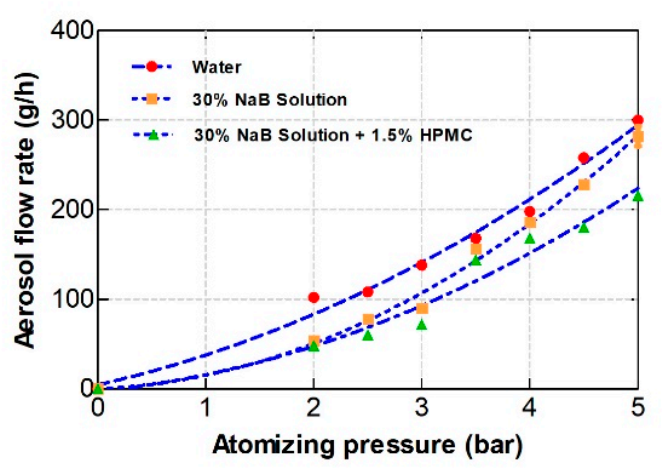

(b)

Figure 2. (a) Volumetric droplet size distributions in different aerosols generated at 5 bar atomizing air pressure; (b) aerosol flow rate vs. atomizing pressure for different liquid solutions.

\subsection{Materials}

\subsubsection{Core Material}

To compare the effects of different particle sizes on the new coating technology, two different sizes of glass particles (Cerablast $\mathrm{GmbH}$, Löchgau, Germany) were used as the core material in the coating experiments. Particle size distributions (PSD) were measured offline by CAMSIZER-XT (Retsch Technologies, Germany). Measured PSD results for each kind of particles are given in Figure 3. The mean diameter was $63 \mu \mathrm{m}$ and $202 \mu \mathrm{m}$, respectively. In both cases, the density of the core particle is $2500 \mathrm{~kg} / \mathrm{m}^{3}$ and sphericity is 0.94 .

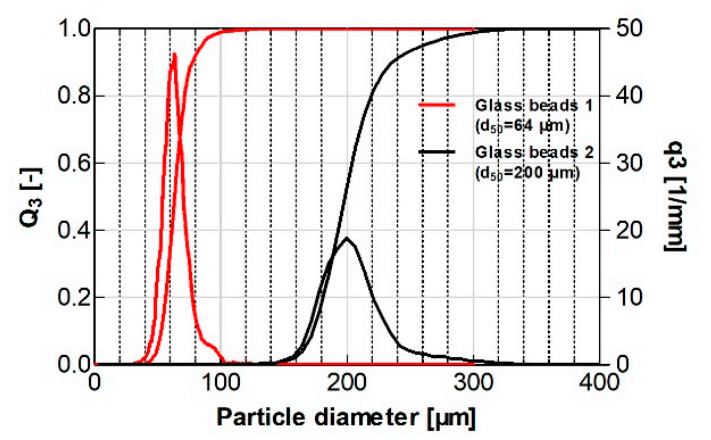

Figure 3. Initial normalized particle size distributions of the two groups of glass particles. 


\subsubsection{Coating Solution}

Sodium benzoate solution was used as a coating agent in these experiments. Sodium benzoate $\left(\mathrm{NaB}, \mathrm{C}_{7} \mathrm{H}_{5} \mathrm{NaO}_{2}\right.$, Trigon Chemie $\mathrm{GmbH}$, Schlüchtern, Germany) is a water-soluble material which is used widely as a preservative in the food industry, but also in academic coating research [26]. To analyze the influence of viscosity of the coating solution, different amounts of hydroxy-propyl-methyl-cellulose (HPMC, trade name Pharmacoat 606, from Shin-Etsu, Tokyo, Japan) were added into the solution. The coating solution density at $20^{\circ} \mathrm{C}$ was measured by using a density measuring device DMA 58 (Anton Paar GmbH, Graz, Austria). A rheometer MCR 302 (Anton Paar GmbH, Graz, Austria) was used to measure the dynamic viscosity of different coating solution with various $\mathrm{NaB}$ content. Both of the devices were calibrated by using distilled water. The solution composition and measured properties are summarized in Table 1.

Table 1. Material properties of coating solution.

\begin{tabular}{ccc}
\hline Solution Composition ${ }^{\mathbf{1}}$ & Density, $\boldsymbol{\rho}_{\mathbf{c s}}\left(\mathbf{k g} / \mathbf{m}^{\mathbf{3}}\right)$ & Viscosity, $\boldsymbol{\eta}_{\mathbf{c s}}(\mathbf{P a} \cdot \mathbf{S})$ \\
\hline $30 \% \mathrm{NaB}$ & 1128.14 & 0.0039 \\
$30 \% \mathrm{NaB}+0.5 \% \mathrm{HPMC}$ & 1129.98 & 0.0062 \\
$30 \% \mathrm{NaB}+1.0 \% \mathrm{HPMC}$ & 1130.01 & 0.0111 \\
$30 \% \mathrm{NaB}+1.5 \%$ HPMC & 1131.90 & 0.0618 \\
\hline \multicolumn{2}{c}{${ }^{1}$ The composition of solution is based on mass fraction (wt $\left.\%\right)}$.
\end{tabular}

\subsection{Fluidized Bed Coating Process}

The coating process of fine particles was conducted in a laboratory-scale fluidized bed (GPCG 1 in Wurster version, Glatt GmbH, Weimar, Germany). The lab-scale set up use the distributer plate which has the diameter of $150 \mathrm{~mm}$ and a $550 \mathrm{~mm}$ cone fluidized chamber. This setup was modified to incorporate a bottom inlet into the chamber providing the inflow of aerosol and mixing with the fluidized particles. The aerosol atomizer in the experiments can well assume the role of the nozzle in the ordinary Wurster fluidized bed (see Figure 4). In the course of the study, the distance between Wurster rises tube and distributer plate was set as $5 \mathrm{~cm}$. Different length of copper tubes (inner diameter: $2.2 \mathrm{~cm}$ ) were installed inside the Wurster rises tube and take place of the nozzle to introduce solution in the fluidized bed.

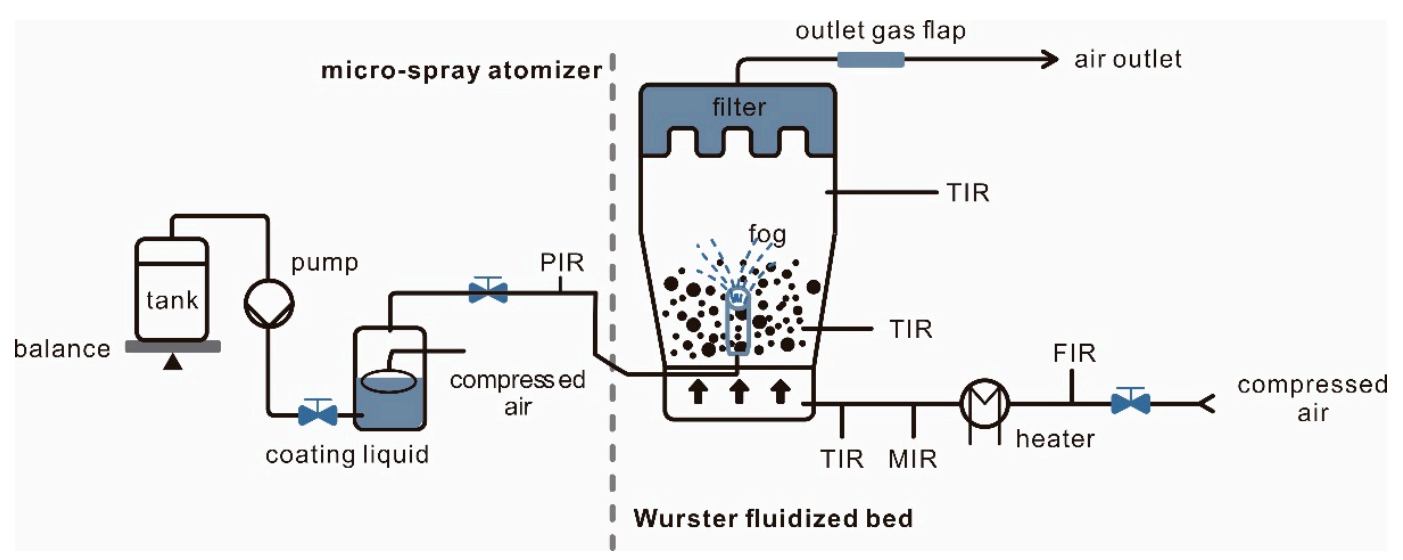

Figure 4. Scheme of the experimental setup using aerosols for particle coating in fluidized bed.

During the experiments, the aerosol and compressed air coming from the aerosol generator were introduced into the fluidized bed system from the bottom through a copper inlet tube. To prevent particles from falling back into the copper tube, its top of was closed. Ten openings with a diameter of $0.5 \mathrm{~cm}$ each were evenly arranged at a distance of $1 \mathrm{~cm}$ from the top. To study the effect of different 
opening heights on the experimental results, different lengths of tubes were used in the experiments. Namely 6, 7, and $8 \mathrm{~cm}$.

In the beginning, $1 \mathrm{~kg}$ of core particles were placed in the fluidized bed and fluidized by hot air at a mass flow rate of $15 \mathrm{~kg} / \mathrm{h}$ for $63 \mu \mathrm{m}$ particles, $23 \mathrm{~kg} / \mathrm{h}$ for $202 \mu \mathrm{m}$ particles. After the temperature in the product vessel was stabilized, the coating solution was sprayed into the fluidized bed. The aerosol atomizer was operated by 5 bar compressed air at room temperature. A peristaltic pump adjusted the liquid level in the coating solution vessel. The operating parameters of each experiment are listed in Table 2. Every $10 \mathrm{~min}$, a sample was taken from the fluidized bed. Every sample was kept in a container for further analysis. After $3 \mathrm{~h}$ of operation, the experiment was finished.

Table 2. Experimental plan.

\begin{tabular}{ccccccc}
\hline Serial & Coating Material & $\begin{array}{c}\text { NaB } \\
\text { Percentage }\end{array}$ & $\begin{array}{c}\text { HPMC } \\
\text { Percentage }\end{array}$ & $\begin{array}{c}\text { Water } \\
\text { Percentage }\end{array}$ & $\begin{array}{c}\text { Air Inlet } \\
\text { Temperature }\end{array}$ & $\begin{array}{c}\text { Copper Tube } \\
\text { Length }\end{array}$ \\
\hline 1 & Glass $(63 \mu \mathrm{m})$ & $30 \%$ & $0 \%$ & $70 \%$ & $70{ }^{\circ} \mathrm{C}$ & $8 \mathrm{~cm}$ \\
2 & Glass $(202 \mu \mathrm{m})$ & $30 \%$ & $0 \%$ & $70 \%$ & $70{ }^{\circ} \mathrm{C}$ & $8 \mathrm{~cm}$ \\
3 & Glass $(63 \mu \mathrm{m})$ & $30 \%$ & $0 \%$ & $70 \%$ & $50{ }^{\circ} \mathrm{C}$ & $8 \mathrm{~cm}$ \\
4 & Glass $(63 \mu \mathrm{m})$ & $30 \%$ & $0 \%$ & $70 \%$ & $60{ }^{\circ} \mathrm{C}$ & $8 \mathrm{~cm}$ \\
5 & Glass $(63 \mu \mathrm{m})$ & $30 \%$ & $0 \%$ & $70 \%$ & $80{ }^{\circ} \mathrm{C}$ & $8 \mathrm{~cm}$ \\
6 & Glass $(63 \mu \mathrm{m})$ & $30 \%$ & $0 \%$ & $70 \%$ & $90{ }^{\circ} \mathrm{C}$ & $8 \mathrm{~cm}$ \\
7 & Glass $(63 \mu \mathrm{m})$ & $30 \%$ & $0.5 \%$ & $69.5 \%$ & $70{ }^{\circ} \mathrm{C}$ & $8 \mathrm{~cm}$ \\
8 & Glass $(63 \mu \mathrm{m})$ & $30 \%$ & $1 \%$ & $69 \%$ & $70{ }^{\circ} \mathrm{C}$ & $8 \mathrm{~cm}$ \\
10 & Glass $(63 \mu \mathrm{m})$ & $30 \%$ & $1.5 \%$ & $68.5 \%$ & $70{ }^{\circ} \mathrm{C}$ & $8 \mathrm{~cm}$ \\
11 & Glass $(63 \mu \mathrm{m})$ & $30 \%$ & $0 \%$ & $70 \%$ & $70{ }^{\circ} \mathrm{C}$ & $7 \mathrm{~cm}$ \\
\hline
\end{tabular}

\subsection{Characterization Methods}

The PSD of each sample taken during the experiment was measured offline by using an optical measurement device, the CAMSIZER-XT (Retsch Technologies, Germany). The PSD is in general an important measure of product quality. Moreover, the accumulated differences in volume frequency between product PSD, $f_{i, p r}$, and raw material PSD, $f_{i, \text { raw }}$, above the point, $\mathrm{m}$, of intersection of those two curves can be used to evaluate the degree of agglomeration. This corresponds to the blue area of Figure 5 and has been proposed in order to quantify agglomeration by Chen et al. [27] as well as by Hample et al. [20]. It should, however, be noted that size enlargement by coating is also captured to a certain extent by $\phi$ obtained from Equation (1).

$$
\phi=\sum_{i \geq m}\left(f_{i, p r}-f_{i, r a w}\right)
$$

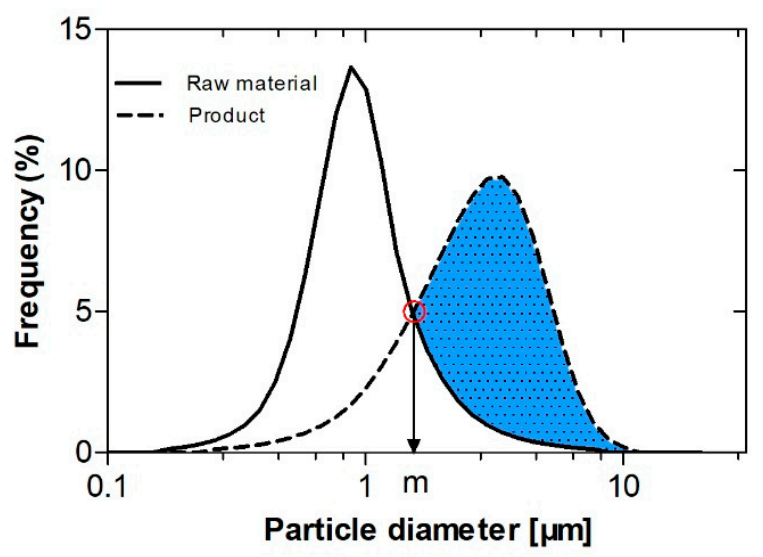

Figure 5. Principle for calculating the agglomeration ratio. 
Moreover, the extent of particle surface coating, which is named coating coverage here, was determined from scanning electron microscopy (SEM) images, taken with a Phenom G2 Pro microscope. Each image used for this purpose contained 35-40 small particles and had a resolution of $1024 \times 1024$ pixels sufficient to identify the coated area. Three images with, in total, 100 particles were typically used for each sample. An analysis was conducted with image identification tools in Python.

The image analysis procedure is shown in Figure 6. In a first step, the image preprocessing was performed by Hough circle detection, which can identify and locate the position of particles in the original image. Particles that were partially outside of the image were discarded. Figure 6a shows the identified particles in the original SEM picture. Applying the particle areas obtained by the pretreatment of the original image, the particles were isolated and the background was cleared. Circle areas were then measured, images were converted to 8-unit images, and a threshold (greyscale to binary) was applied. The above step successfully removed the noise caused by reflection. Subsequently, the coating coverage was calculated as the proportion of black pixels within the circular image areas that correspond to identified particles, see Figure $6 \mathrm{~b}$. To eliminate the impact of the inability to accurately identify the edge pixels of the particles on the results, only the central part of each particle in the original image was used in the calculation process, that is, the region whose radius was $80 \%$ of the initial radius. Please note that SEM images are planar, so there would be errors in the directly calculated coverage due to the curvature of the particles. To eliminate this effect, a geometrical correction was applied to the pictures. The respective change of $S_{3 D}$ (surface area on sphere) to $S_{2 D}$ (visible area) with the distance from particle center can be seen in Figure 6c. In this study, to eliminate the blurring of the circular border, evaluation has been conducted by dividing the central area ( $80 \%$ based on diameter) of each particle into ten parts, see Figure 6d.

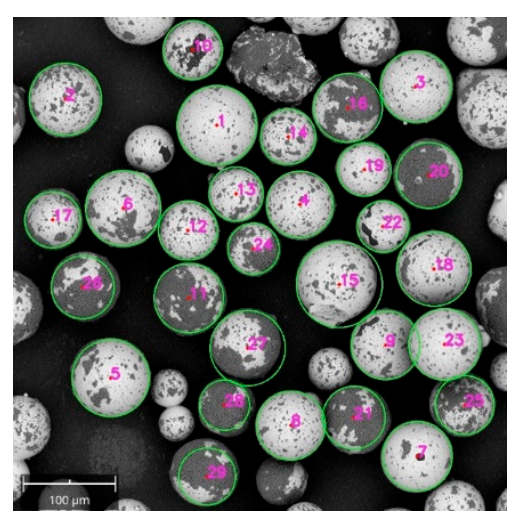

(a)

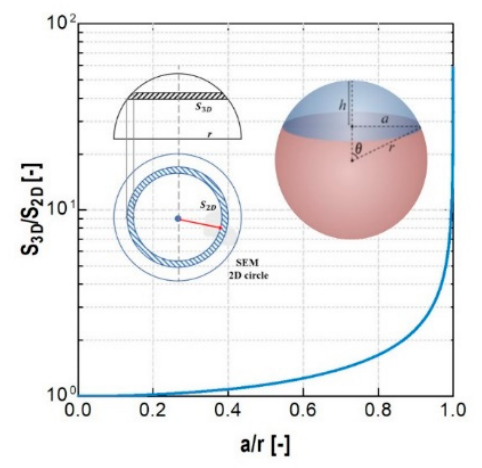

(c)

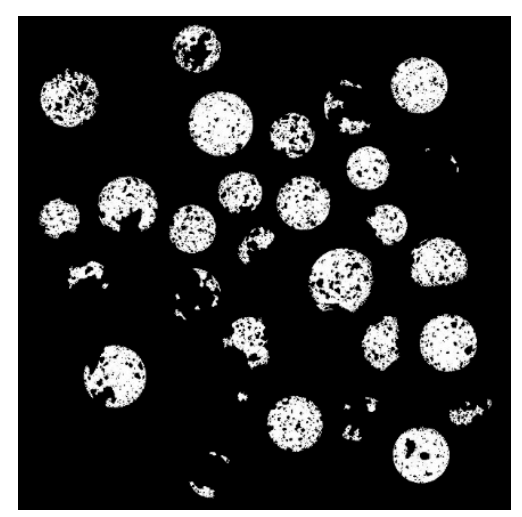

(b)

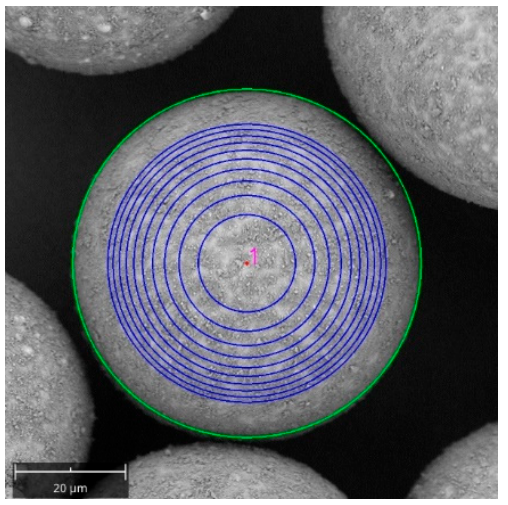

(d)

Figure 6. (a) Pretreatment of SEM pictures by Hough circle detection. (b) Processed binary picture for the calculation of coating coverage. (c) Ratio of $S_{3 D}$ to $S_{2 D}$ with respect to the distance to particle center. (d) Area subdivision of the image error elimination method. 
For further analysis, the yield of the coating process $Y$ was also calculated. For this purpose, at first, each of the samples taken from the product was dried in an oven to get the dry mass $M_{1}$ of coated particles accurately. Subsequently, the coating layers were totally removed by soaking and stirring the sample in distilled water for $24 \mathrm{~h}$. The second desired mass $M_{2}$ was obtained after the core particles dried again. Combined the total sprayed amount $M_{s}$ and raw material mass $M_{r}$ process yield can then be calculated as:

$$
\begin{gathered}
Y=\frac{\left(M_{1}-M_{2}\right) / M_{2}}{R_{\text {coating, } \max }}, \\
R_{\text {coating, } \max }=\frac{M_{s}}{M_{r}},
\end{gathered}
$$

\section{Results and Discussion}

The coating process in a fluidized bed is complex. It involves an ingenious balance between mixing, wetting and drying, which depends on several parameters such as air temperature and flow rate, sprayed solution rate, coating solution composition and many other factors [1,28-30]. All the above variables have a decisive effect on the quality of the product. Comprehensive experimental and numerical research has been done in the past few years for large particles coated in fluidized beds with conventional nozzles to explain the effect of these variables.

From the past studies it is clear that: (1) the rise of inlet air temperature enhances the drying of wet particles during the coating; (2) more uniform dispersion of coating solution droplets in the equipment results in more uniform layers on the particle surfaces; (3) growth of coating layer thickness depends on the flow rate of the coating solution. Despite the many results on the coating of large particles (diameter $>200 \mu \mathrm{m}$ ) in the literature, less attention has been paid to the investigation of the coating parameters of fine particles. However, with the help of the novel aerosol atomizer, the coating of fine particles is easier, so it is possible to make a systematic investigation of the effects of important operating parameters on the coating performance.

\subsection{Effect of Particle Size}

As mentioned earlier, large particles and small particles usually behave differently in fluidized bed coating. This difference is usually caused by the imperfect fluidization of small particles. In this study, in order to enhance the fluidization of small particles, the Wurster fluidized bed was used. At the same time, the new aerosol generator was also applied in the coating process for both kinds of particles. The experimental results show that both large and small particles could be coated under the usage of aerosol, but there are still some differences.

Particle size distributions of uncoated and coated glass particles are plotted in Figure 7a. Average particle sizes of small and large coated particles are $66 \mu \mathrm{m}$ and $215 \mu \mathrm{m}$ respectively, with the original particles at $63 \mu \mathrm{m}$ and $202 \mu \mathrm{m}$, as mentioned before. This implied that most of the particles were individually coated. In addition, the agglomeration rate $\phi$ were $5.4 \%$ and $6.8 \%$, respectively, when using the calculation method from Section 2.4. These results all prove that both large particles and small particles could be successfully coated without severe agglomeration by the novel method.

Figure $7 \mathrm{~b}$ shows the evolution of the average particle diameter for the product samples. The absolute growth value of large particles is higher than that of small particles. On the other hand, the growth interval of small particles is mainly concentrated in the first 40 min and particle diameter is stabilized after that, while large particles can continue to grow for nearly $90 \mathrm{~min}$. 


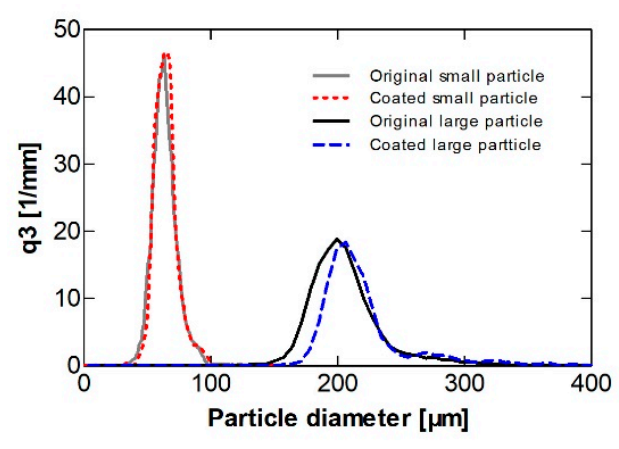

(a)

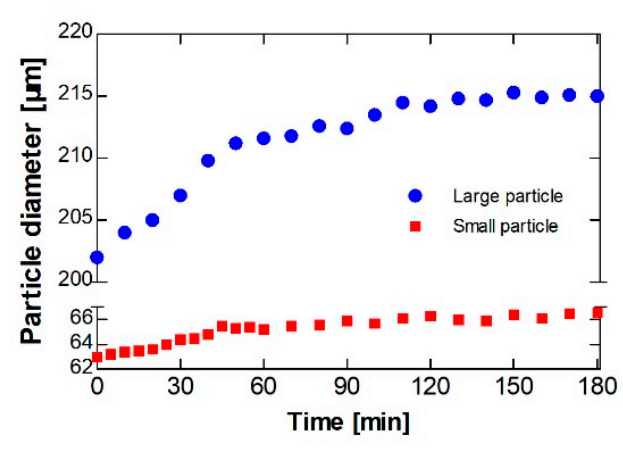

(b)

Figure 7. (a) Particle size distributions, and (b) evolution of average particle diameter $d_{1,3}$ for particles of different size.

SEM images with different magnification of product (shown in Figure A1 of Appendix A) reveal the larger and smaller glass beads were both coated by $\mathrm{NaB}$, proving the successful coating of particles by the novel coating process with aerosol. The corresponding coating coverage as shown in Figure 8 reveals that both large and small particles were almost completely covered, with the mean coverage value of large particles being $99.2 \%$ and that of small particles being $99 \%$. Since this is close to unity, the coverage had a very small standard deviation in both cases.

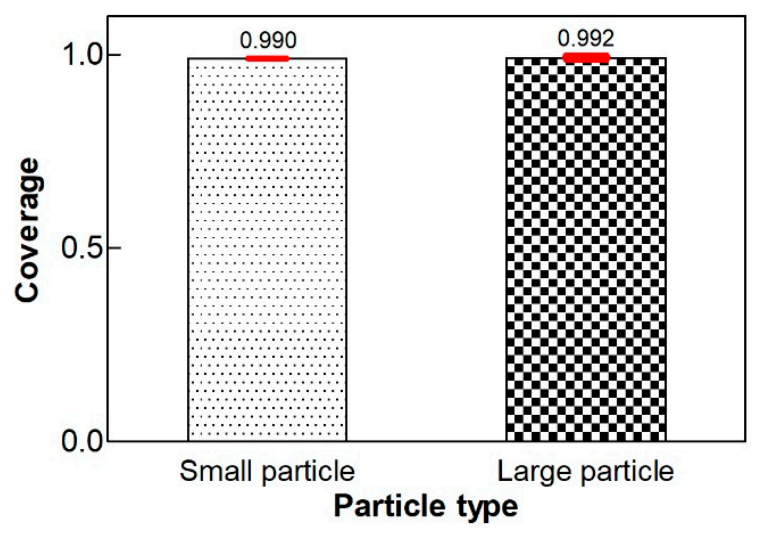

Figure 8. Coverage comparison based on particle size.

Smaller particle size results in a relatively lower yield, as shown in Table 3; $13.59 \%$ for glass cores of $63 \mu \mathrm{m}$ as compared with $21.51 \%$ for glass cores of $202 \mu \mathrm{m}$. The loss of coating material is mainly attributed to the collected fines in the filter above the fluidized bed. Because the droplet size of the aerosol is extremely small, it was easy to be dried by hot air and entrained to the filter by the fluidization gas.

Table 3. Yield of aerosol coating process with different particles ${ }^{1}$.

\begin{tabular}{cccc}
\hline Particle Type & Mass of Cores $(\mathrm{g})$ & Coating Mass $(\mathrm{g})$ & Yield $^{(\mathbf{\%}) \mathbf{~}^{\mathbf{2}}}$ \\
\hline Small particle & $2.5010 \pm 0.55$ & $0.0849 \pm 0.017$ & 13.59 \\
Large particle & $2.0592 \pm 0.16$ & $0.1122 \pm 0.012$ & 21.51
\end{tabular}

${ }^{1}$ Total mass of glass beads: $1000 \mathrm{~g}$; Mean aerosol spray rate: $282 \mathrm{~g} / \mathrm{h} .{ }^{2}$ Average value from three samples.

From the above results, it can be seen that both large and small particles can be properly fluidized in the modified Wurster equipment, and uniform coating can be obtained when the aerosol generator replaces the conventional two-fluid nozzle. However, it is worth noting that due to the extremely small size of the aerosol, it takes a longer time for the core particles to obtain an almost 
complete coating compare to the conventional coating process. Moreover, according to experimental observations, small particles would rather stick to the wall of the fluidized bed due to electrostatic and other micro-scale forces, which might explain why the coverage rate is slightly lower than that of large particles.

\subsection{Effect of Air Inlet Temperature}

Hot fluidized gas passing through the distributor plate and the fluidization chamber is responsible for drying of the particles by heat and mass transfer to the fluidized bed. Based on previous experience, higher temperature during the process favors drying, leading to rapid evaporation of droplets. In comparison, when temperature is lower, the evaporation rate of the coating solution decreased, leading to slight agglomeration. A moderate coating process in the modified fluidized bed is only obtained when wetting and drying reached a proper balance. The above conclusions are also applicable to the use of traditional nozzles for large particles. However, the balance is more difficult to maintain when using fine particles, and the temperature control the coating of fine fluidized particles using the aerosol generator is more challenging.

The particle size distribution results for small glass particles when air inlet temperature increased from $50{ }^{\circ} \mathrm{C}$ to $90{ }^{\circ} \mathrm{C}$ are plotted in Figure 9a. Product size does not have obvious differences as temperature changes; mean particle size is $67.5 \mu \mathrm{m}, 66.8 \mu \mathrm{m}, 66 \mu \mathrm{m}, 65.7 \mu \mathrm{m}$ and $65.8 \mu \mathrm{m}$ respectively. Figure $9 \mathrm{a}$ also indicates the slight difference of agglomeration ratios $(13.1 \%, 8.6 \%, 5.4 \%, 3.6 \%$ and $3.4 \%$ based on the PSD results). It can be seen that the overall agglomeration rate is at a relatively low level, but there are still more agglomerated particles under low temperature conditions than at high temperature.

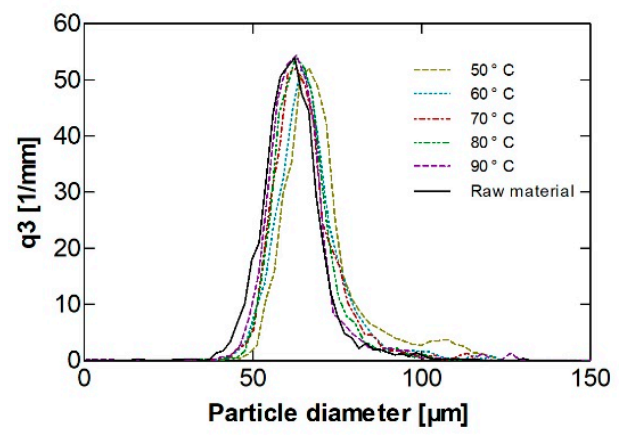

(a)

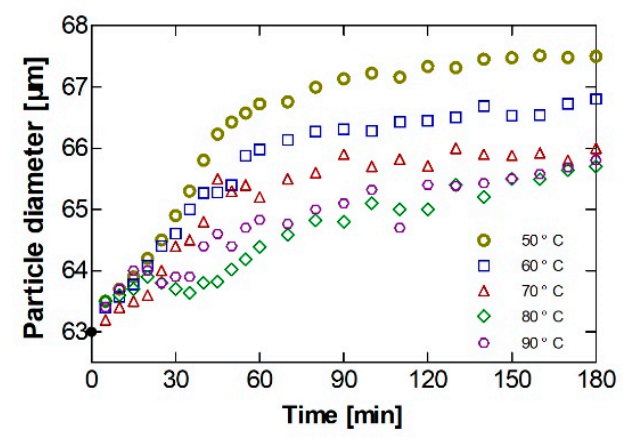

(b)

Figure 9. (a) Particle size distributions, and (b) evolution of average particle diameter $\mathrm{d}_{1,3}$ at different temperatures.

As depicted in Figure 9b, in each case, faster growth is achieved at the beginning of the experiment. After $60 \mathrm{~min}$, average particle size is still increasing. The process is stopped at $180 \mathrm{~min}$ with fluctuating average particle diameters of approximately $66 \mu \mathrm{m}$ in the product.

SEM images shown in Figure A2 of Appendix A that clearly illustrate that during the coating process in the modified fluidized bed, agglomeration hardly happened. At the lowest temperature of $50{ }^{\circ} \mathrm{C}$, coating quality was though worse than at higher temperature. When particles are coated at a higher temperature, the images show a better coating structure. To differentiate the coating performance at the above five temperatures, coating coverage calculation based on SEM images has been carried out and the results are shown in Figure 10. It is seen that the coating coverage tends to increase with the fluidized bed temperature, though with a maximum at $70{ }^{\circ} \mathrm{C}$ (with coating coverage of $86 \%$ for $50{ }^{\circ} \mathrm{C}, 88 \%$ for $60{ }^{\circ} \mathrm{C}, 99 \%$ for $70{ }^{\circ} \mathrm{C}, 94 \%$ for $80^{\circ} \mathrm{C}$ and $92 \%$ for $90^{\circ} \mathrm{C}$ ). 


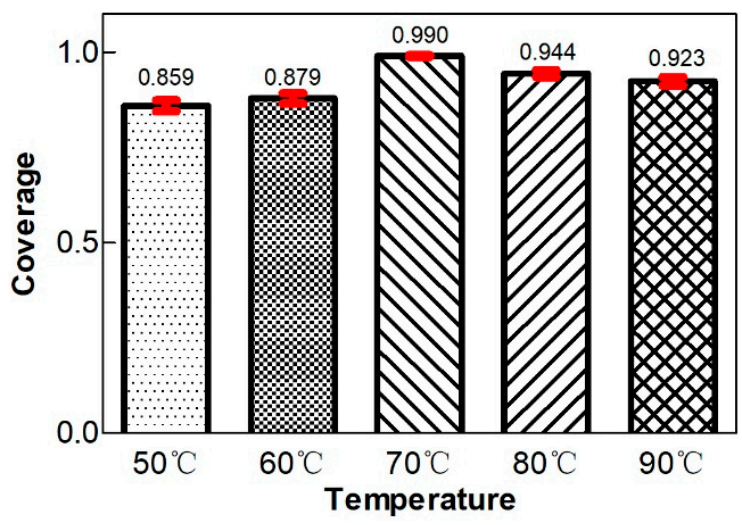

Figure 10. Coverage comparison based on temperature.

The influence of temperature on the yield of the aerosol coating process is shown in Table 4 . The results indicate that when the temperature is too high, the yield may be much lower than at moderate temperature; $13.59 \%$ for the temperature of $70^{\circ} \mathrm{C}$ as compared with $8.83 \%$ for the temperature of $90{ }^{\circ} \mathrm{C}$. It is known that temperature may be a critical factor that can affect process yield even when using a two-fluid nozzle. In fact, when the aerosol generator is used, because the aerosol has smaller droplet size, the temperature causes a more noticeable effect on the yield. Higher temperature results in the loss of coating material due to rapidly evaporation before deposition and coating can take place on the surface of the cohesive fluidized particles, which allows the aerosol droplets to be directly dried into fine powder and then quickly blown out of the fluidization chamber with the airflow.

Table 4. Yield of aerosol coating process at different temperatures ${ }^{1}$.

\begin{tabular}{cccc}
\hline Temperature $\left({ }^{\circ} \mathbf{C}\right)$ & Mass of Cores $(\mathrm{g})$ & Coating Mass $(\mathrm{g})$ & Yield $(\mathbf{\%})^{\mathbf{2}}$ \\
\hline 50 & $2.0113 \pm 0.07$ & $0.0772 \pm 0.015$ & 14.48 \\
60 & $2.2572 \pm 0.37$ & $0.0779 \pm 0.002$ & 14.22 \\
70 & $2.5010 \pm 0.55$ & $0.0849 \pm 0.017$ & 13.59 \\
80 & $1.8998 \pm 0.16$ & $0.0435 \pm 0.012$ & 9.08 \\
90 & $1.3141 \pm 0.05$ & $0.0293 \pm 0.041$ & 8.83
\end{tabular}

${ }^{1}$ Total mass of glass beads: $1000 \mathrm{~g}$; Mean aerosol spray rate: $282 \mathrm{~g} / \mathrm{h} .{ }^{2}$ Average value from three samples.

In summary, it can be seen that the evaluation indicators of coated products are susceptible to temperature changes. At low temperature, some aerosol droplets cannot be dried in time. So even though the droplets are very small when the aerosol generator is applied, liquid bridges between the particles may still lead to agglomeration. On the contrary, agglomeration is negligible at high temperature, but the loss of coating solution by overspray may cause lower solution yield. Therefore, in the case of various process parameters being adjusted, it is particularly important to first determine an appropriate range of mild temperatures to obtain high-quality products.

\subsection{Effect of Coating Solution Viscosity}

To investigate the influence of coating solution viscosity on coating speed and process time with the same core particles as before, an additive was mixed into the coating solution. As mentioned above, the additive used was HPMC, which is suitable for the agglomeration of excipients and also plays an important role as a coating material in the pharmaceutical industry. The concentration of HPMC in the solution should be carefully selected. Due to its extremely high viscosity, HPMC is usually used as an agglomerating binder with more than $4 \mathrm{wt} \%$ in the solution [31]. In this study of coatings, less HPMC was added to the $\mathrm{NaB}$ solution, namely zero to $1.5 \%$.

The influence of coating solution viscosity on coating performance was experimentally investigated by adding different mass fraction of HPMC (with a relationship between HPMC mass fraction and 
solution viscosity, as can be seen in Table 1), and the corresponding results are discussed in the following. Figure 11a indicates that more HPMC in the solvent makes the size distribution of coated glass particles slightly different and somewhat narrows. The average size of the final coated particles decreased monotonically from $66 \mu \mathrm{m}$ to $64.8 \mu \mathrm{m}$ when the HPMC mass fraction in the NaB solution was increased from $0 \%$ to $1.5 \%$. Figure $11 \mathrm{~b}$ shows the evolution of average particle size with different viscosity of the coating solution. In these experiments, a much more quicker particle growth is achieved when the coating solution has a higher viscosity. A fluctuating steady state is reached in only $20 \mathrm{~min}$ for $1.5 \mathrm{wt} \%$ HPMC, compared to $40 \mathrm{~min}$ for $0 \%$ HPMC. On the other hand, higher solution viscosity results in smaller final particle size. The process stops after $180 \mathrm{~min}$ with particle size growth from $1.8 \mu \mathrm{m}$ to $3 \mu \mathrm{m}$.

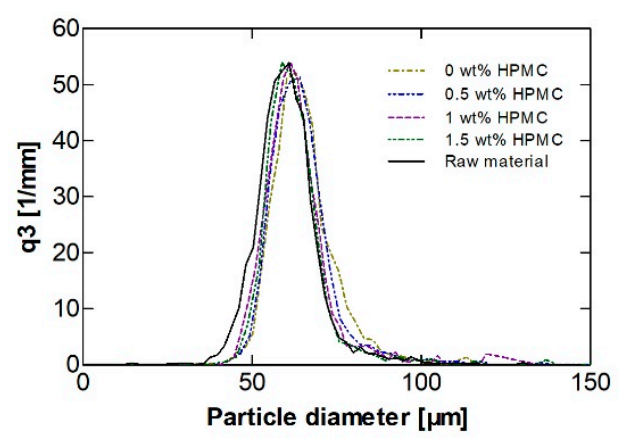

(a)

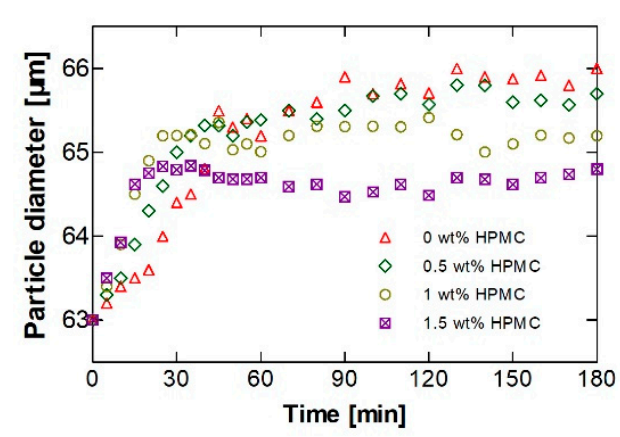

(b)

Figure 11. (a) Particle size distributions and (b) evolution of average particle diameter $\mathrm{d}_{1,3}$ for different HPMC concentrations.

With traditional two-fluid nozzles, higher viscosity of the coating solution can increase the rate of undesired agglomeration in the course of coating processes. However, the novel aerosol atomizer can generate small aerosol droplets, which makes it difficult to produce solid bridges at a suitable process temperature even when the solution viscosity is high. The present results confirm that the agglomeration rate remains small even at high viscosity of the coating solution (agglomeration rate of $2.99 \%$ for $0.5 \mathrm{wt} \%$ HPMC, $2.32 \%$ for $1 \mathrm{wt} \%$ HPMC and $1.24 \%$ for $1.5 \mathrm{wt} \%$ HPMC based on the PSD).

SEM images of coated particles are shown in Figure A3 of the Appendix A. It appears that the increase in viscosity of the solution decreases significantly the overall average coverage of particles, with increasing differences among individual particles of the population. In general, island growth is observed, and patchy particles are obtained. In the case of $1.5 \mathrm{wt} \%$ HPMC, the overall coverage is only $21 \%$. In addition to the decrease in coverage, the coating layers also gradually become compact and brittle as the viscosity increases. Figure 12 shows the coverage results evaluated from the SEM images at different HPMC concentrations.

As the solution viscosity increases, the coverage shows a downward trend. One explanation is that after the high-viscosity liquid dries on the surface of the particles, the dense and compact coating layers break off due to collisions between particles. Finally, the growth and breakage of the coating layer reach an equilibrium at a certain surface coverage, which may be quite low. To verify this conjecture, an additional experiment has been conducted with $5 \mathrm{wt} \%$ of HPMC. During this experiment, the yield of the solution has been evaluated every $10 \mathrm{~min}$. Results are plotted in Figure 13. It can be seen that the yield decreases to zero $60 \mathrm{~min}$, that is, the rate of coating layer formation becomes equal to the rate of dried coating layer breakage. This trend is stronger when introducing HPMC to increase the viscosity of the solution; it is, therefore, not easy to obtain a coating product with $100 \%$ coverage in such cases. 


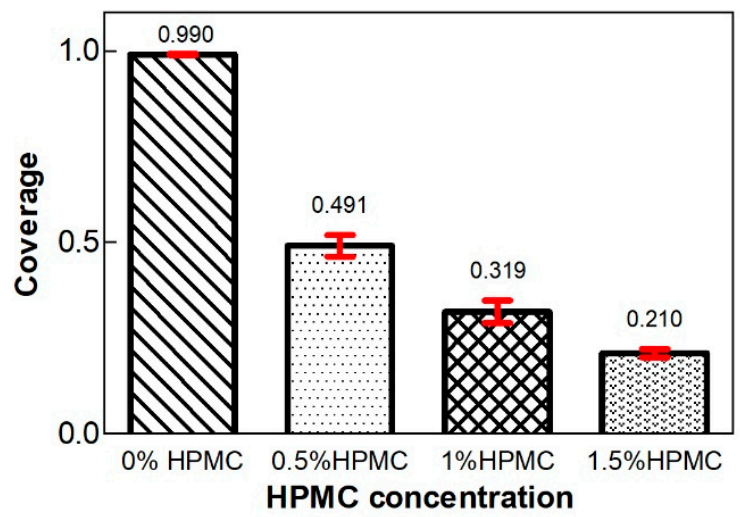

Figure 12. Coverage comparison based on HPMC concentration

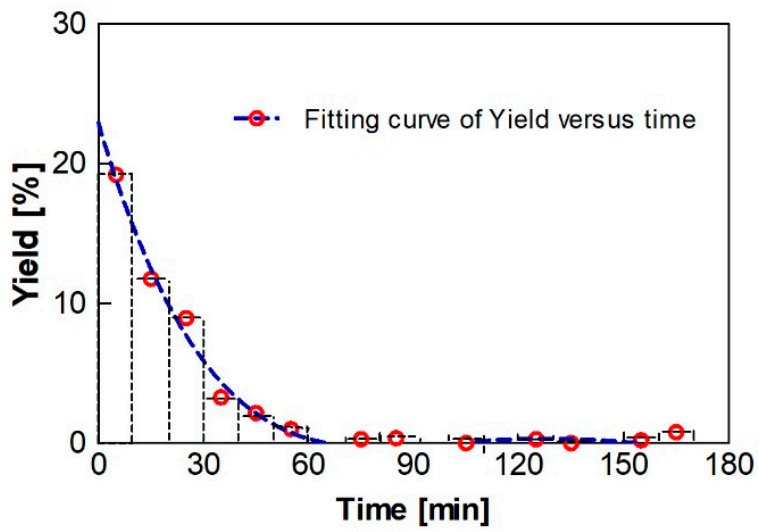

Figure 13. Coating solution yield versus process time.

In summary, agglomeration can be avoided by the innovative coating system even when the particles are fine and the coating solution is sticky. Sticky solution may even increase the coating rate by promoting the deposition of aerosol droplets on the surface of core particles. At the same time, however, coating layers are denser and more compact than at low viscosity. Such dense coating layers seem to be brittle, and are more likely to break off after collisions between particles and with walls in the Wurster fluidized bed, which results in low product coverage and uneven overall coating of patchy product particles.

\subsection{Effect of Aerosol Inlet Position}

In this study, the aerosol was introduced into the fluidized bed from the bottom by means of a copper inlet tube through the distributor plate. When using a Wurster fluidized bed with a traditional two-fluid nozzle, the distance between the nozzle outlet and the bottom distributor plate can affect the coating quality. Similarly, in the novel coating system, aerosol and fluidized particles move concurrently in riser, so the inlet position of aerosol may affect its contact time with the particles. Therefore, the influence of aerosol inlet position on the experimental results was explored using three different copper tubes with lengths of $6 \mathrm{~cm}, 7 \mathrm{~cm}$ and $8 \mathrm{~cm}$, respectively.

As can be seen from the particle size distributions in Figure 14, the inlet tube of $8 \mathrm{~cm}$ has a minor effect in altering the particle size, showing scarce agglomeration and only a slight change in average particle size. With a decrease of the inlet tube length to $7 \mathrm{~cm}$, the amount of larger agglomerates increased slightly. Results based on calculated from graphs verify that decreasing the tube length from $8 \mathrm{~cm}$ to $6 \mathrm{~cm}$ results in a slightly increased particle size from $66 \mu \mathrm{m}$ to $67.5 \mu \mathrm{m}$, and the proportion of agglomeration increases significantly from $5.4 \%$ to $13.2 \%$. The reason for this behavior is that the 
shorter tube increases the residence time of droplets in the Wurster riser, but it also increases the humidity in regions with many particles, so agglomeration is more likely to occur.

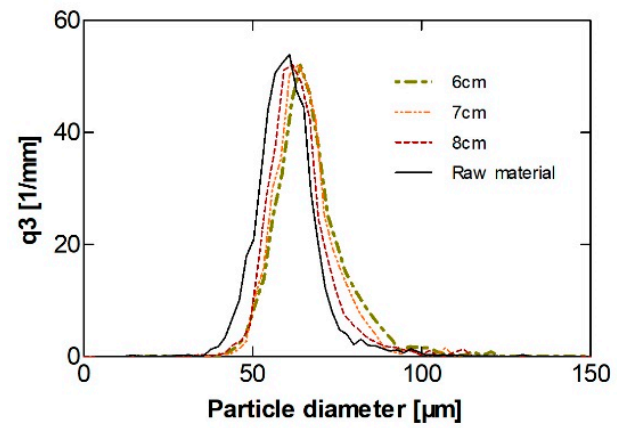

(a)

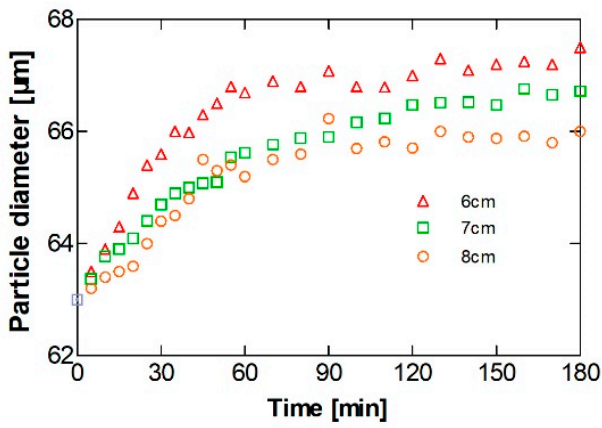

(b)

Figure 14. (a) Particle size distributions and (b) evolution of average particle diameter $d_{1,3}$ for different aerosol inlet tube lengths.

As depicted in Figure 14b, the experiment reaches steady state after around 60 min with average particle size of approximately $67.5 \mu \mathrm{m}$ in the product when the copper tube is $6 \mathrm{~cm}$. Compared to the $7 \mathrm{~cm}$ and $8 \mathrm{~cm}$ experiments, the growth rate is faster at beginning, and the average particle size is slightly larger at steady state.

SEM images of the final product (Appendix A, Figure A4) show good coating of the glass particles for all investigated aerosol inlet tube lengths. The related coating coverage shown in Figure 15 ranges from $99.8 \%$ to $99 \%$. All three conditions have a small standard deviation, which means the particle coverage is relatively uniform.

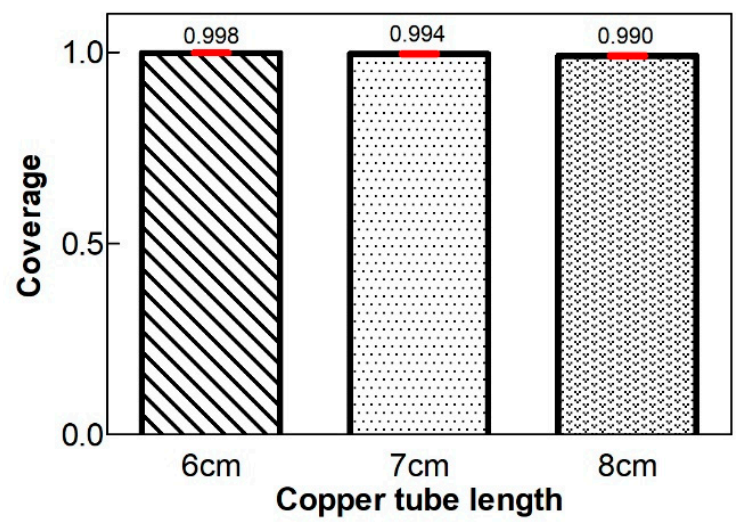

Figure 15. Coverage comparison based on length of aerosol inlet tube.

Table 5 indicates that a longer aerosol tube results in lower yield; $13.59 \%$ for a copper tube of $8 \mathrm{~cm}$ as compared with $23.13 \%$ for $6 \mathrm{~cm}$. It can be seen that the closer the aerosol outlet is to the bottom distributor plate, the less coating solution is lost; therefore, the use rate is the highest in this case.

Table 5. Yield of aerosol coating process with different aerosol inlet tubes ${ }^{1}$.

\begin{tabular}{cccc}
\hline Inlet Tube Length $(\mathbf{c m})$ & Mass of Cores $(\mathbf{g})$ & Coating Mass $(\mathrm{g})$ & Yield $^{(\boldsymbol{\%})} \mathbf{~}^{\mathbf{2}}$ \\
\hline 6 & $1.6187 \pm 0.51$ & $0.0697 \pm 0.015$ & 23.13 \\
7 & $5.1553 \pm 0.21$ & $0.0848 \pm 0.009$ & 17.47 \\
8 & $2.5010 \pm 0.55$ & $0.0849 \pm 0.017$ & 13.59
\end{tabular}

\footnotetext{
${ }^{1}$ Total mass of glass beads: 1000 g; Mean aerosol spray rate: $282 \mathrm{~g} / \mathrm{h} .{ }^{2}$ Average value from three samples.
} 
The above results show that, similar to the conventional bottom spray coating system, when the coating process is conducted with the novel aerosol generator, the position at which the generated aerosol is introduced into the fluidized bed influences the results. Due to higher particle concentration at the bottom of the Wurster fluidized bed [32], when aerosol enters the fluidized bed at a lower position, the frequency of contacts with particles and the probability of particles capturing aerosol droplets rise. Eventually, the process yield will also increase. However, it is worth noting that a too-low inlet position will also cause the humidity of the dense zone of bed to increase, with a potential increase in the agglomeration.

\section{Conclusions}

A novel coating process in a Wurster fluidized bed combined with an aerosol atomizer was presented in this study. It was shown by a series of experiments that different operation parameters influence the particle growth behavior. The experiments have shown the feasibility of using aerosol to produce a coating layer on fluidized particles. It should be noted that submicron aerosol droplets have been used rather than conventional two-fluid nozzle spray with droplet diameters of tens of microns. Due to the extremely small diameter of aerosol droplets, even very small core particles could be individually coated and without severe agglomeration. In addition, in the industrial field, due to the extremely small aerosol droplets, the resulting coating layer is ultrathin, and the yield of the new coating process was determined to be $15-20 \%$ under different conditions, which is considered to be improvable. The yield in this study may be enhanced by the recycling of entrained solids or better equipment design, especially when scaling up the experiment plant.

Coating performance was characterized from both microscale (SEM) and macroscale (PSD, yield) points of view. Different operation parameters such as particle size, air temperature, coating solution viscosity and aerosol inlet position in the Wurster riser have an influence on product quality. The main conclusions are as follows:

- Both conventionally large particles and smaller particles that are difficult to coat in conventional equipment can be coated without agglomeration in a Wurster fluidized bed with the help of an aerosol generator. The highest growth rate is observed at the beginning of the novel process. Over time, the growth rate decreases gradually until a quasi-steady state has been reached.

- The temperature of the fluidizing gas has a significant impact on the quality of the coated product. A decrease in temperature may increase the agglomeration rate, while excessively high temperature will lower the use of coating solution and the coating rate. Moderate temperature can maintain reasonable yield and low agglomeration ratio.

- Particle growth rate was observed to increase with the increase of coating solution viscosity. Higher viscosity aerosol is easier to adhere to the particles. Unfortunately, this is accompanied by the creation of compact and dense coating layers, which are more likely to break down due to collisions with other particles and walls in the Wurster fluidized bed. Equilibrium between coating layer growth and breakage may result in lower coverage when the solution viscosity is high, and in patchy product particles.

- The position where coating aerosol is introduced into the fluidized bed has an impact on the use rate of the coating solution. When aerosol is fed close to the bottom distributor plate, it interacts with the particles in a dense zone of the equipment, hence the use rate is higher. Meanwhile, the agglomeration rate also slightly increases.

In summary, the use of very small aerosol droplets enables the coating of fine particles without severe agglomeration in a Wurster fluidized bed. This novel approach of potential interest for pharmaceutical, food, catalyst and other industries, where it may contribute to the development of new products based on coated fine particles. 
Author Contributions: R.Z. carried out the experiment. R.Z. wrote the manuscript with support from T.H. and E.T., T.H. and E.T. helped supervise the project. E.T. and R.Z. conceived the original idea. All authors have read and agreed to the published version of the manuscript.

Funding: The first author gratefully acknowledges the funding of this work by the China Scholarship Council (NO. 201708080202).

Acknowledgments: We also thank Jing Yang for his assistance in the conduction of the experiments and measurements of samples in the frame of his M.Sc. thesis.

Conflicts of Interest: The authors declare no conflict of interest.

\section{Appendix A}

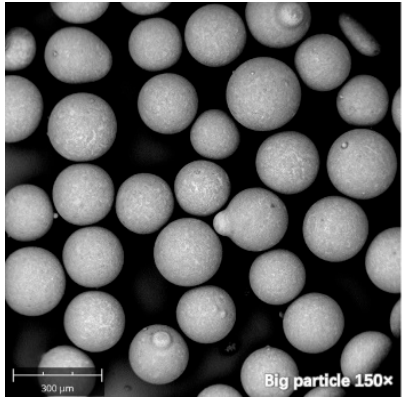

(a)

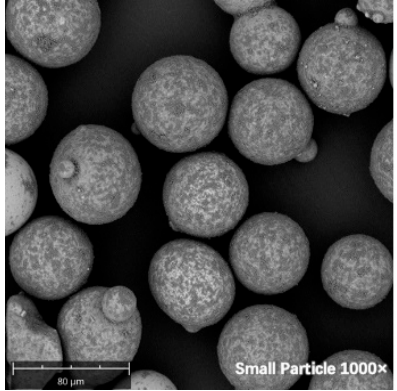

(b)

Figure A1. SEM images from experiments using (a) large particles; (b) small particles.

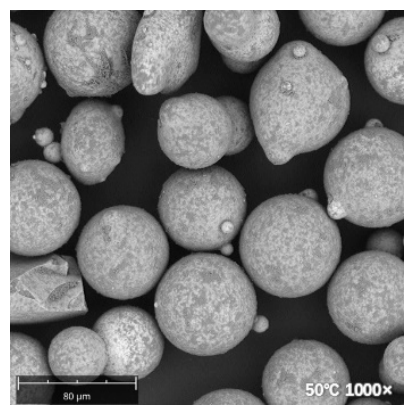

(a)

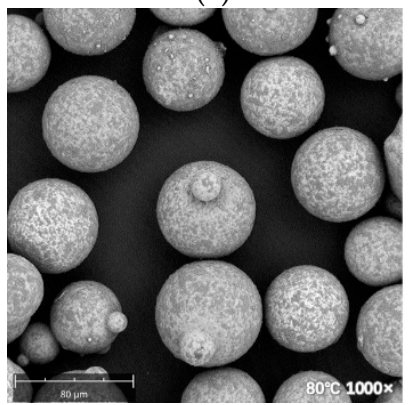

(d)

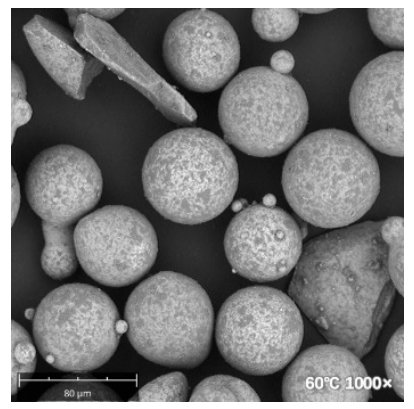

(b)

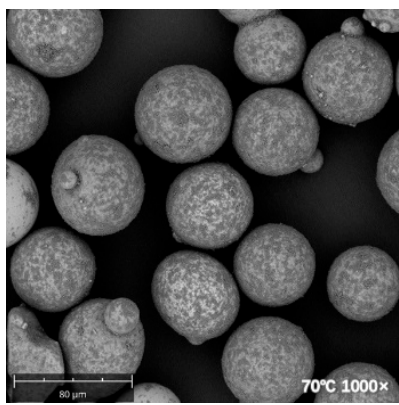

(c)

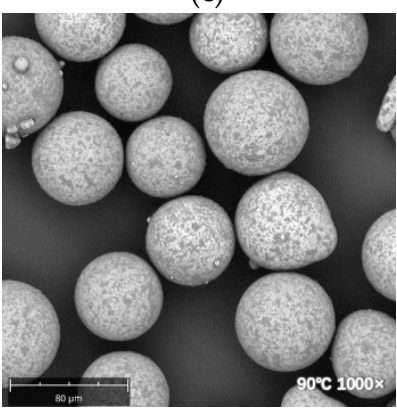

(e)

Figure A2. SEM images from experiments under different fluidization temperatures (a) $50{ }^{\circ} \mathrm{C}$; (b) $60^{\circ} \mathrm{C}$; (c) $70{ }^{\circ} \mathrm{C}$; (d) $80{ }^{\circ} \mathrm{C}$; (e) $90^{\circ} \mathrm{C}$. 


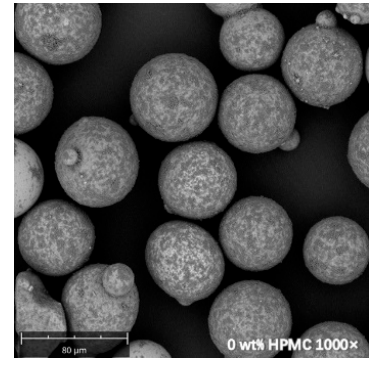

(a)

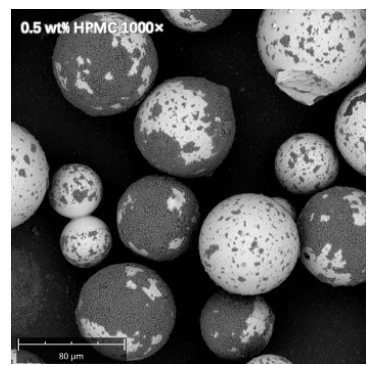

(c)

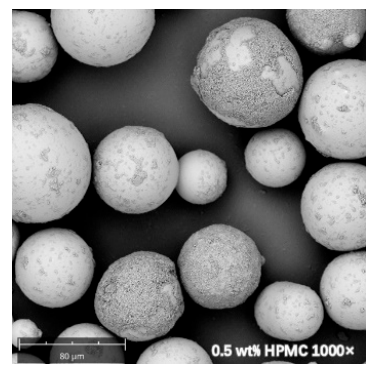

(b)

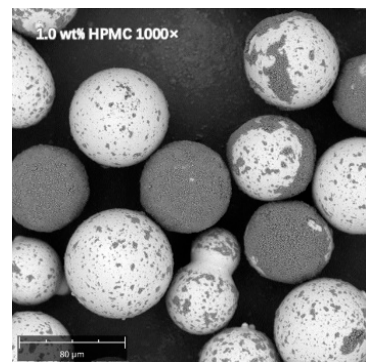

(d)

Figure A3. SEM images from experiments using various HPMC mass fractions of the coating solution (a) $0 \mathrm{wt} \%$; (b) $0.5 \mathrm{wt} \%$; (c) $1.0 \mathrm{wt} \%$; (d) $1.5 \mathrm{wt} \%$.

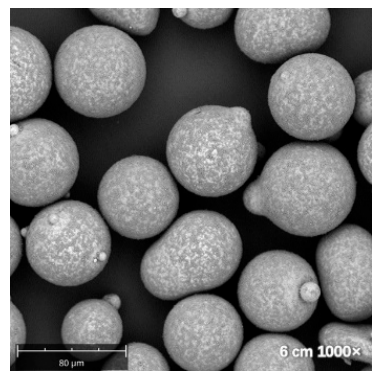

(a)

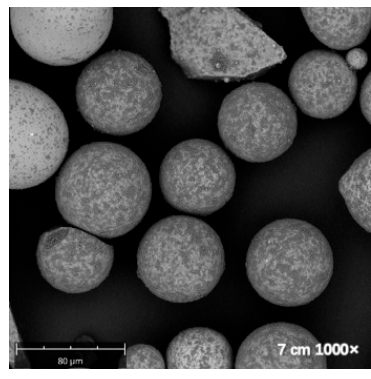

(b)

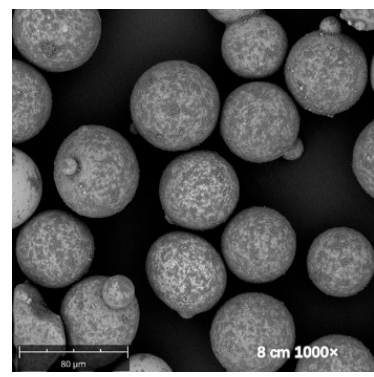

(c)

Figure A4. SEM images from experiments using various lengths of the aerosol inlet tube (a) $6 \mathrm{~cm}$; (b) $7 \mathrm{~cm}$; (c) $8 \mathrm{~cm}$.

\section{References}

1. Kleinbach, E.; Riede, T. Coating of solids. Chem. Eng. Process. Process. Intensif. 1995, 34, 329-337. [CrossRef]

2. Felton, L.; Timmins, G. A nondestructive technique to determine the rate of oxygen permeation into solid dosage forms. Pharm. Dev. Technol. 2006, 11, 141-147. [CrossRef] [PubMed]

3. Porter, S.C.; Felton, L.A. Techniques to assess film coatings and evaluate film-coated products. Drug Dev. Ind. Pharm. 2010, 36, 128-142. [CrossRef] [PubMed]

4. Goslinska, M.; Selmer, I.; Kleemann, C.; Kulozik, U.; Smirnova, I.; Heinrich, S. Novel technique for measurement of coating layer thickness of fine and porous particles using focused ion beam. Particuology 2019, 42, 190-198. [CrossRef]

5. Dewettinck, K.; Huyghebaert, A. Fluidized bed coating in food technology. Trends Food Sci. Technol. 1999, 10, 163-168. [CrossRef]

6. Watano, S.; Imada, Y.; Hamada, K.; Wakamatsu, Y.; Tanabe, Y.; Dave, R.N.; Pfeffer, R. Microgranulation of fine powders by a novel rotating fluidized bed granulator. Powder Technol. 2003, 131, 250-255. [CrossRef]

7. Jones, D.M. Factors to consider in fluid-bed processing. Pharm. Technol. 1985, 9, 50-55.

8. Rieck, C.; Bück, A.; Tsotsas, E. Monte Carlo modeling of fluidized bed coating and layering processes. AIChE J. 2016, 62, 2670-2680. [CrossRef]

9. Pietsch, S.; Peter, A.; Wahl, P.; Khinast, J.; Heinrich, S. Measurement of granule layer thickness in a spouted bed coating process via optical coherence tomography. Powder Technol. 2019, 356, 139-147. [CrossRef] 
10. Geldart, D. Types of gas fluidization. Powder Technol. 1973, 7, 285-292. [CrossRef]

11. Rieck, C.; Hoffmann, T.; Bück, A.; Peglow, M.; Tsotsas, E. Influence of drying conditions on layer porosity in fluidized bed spray granulation. Powder Technol. 2015, 272, 120-131. [CrossRef]

12. Ennis, B.J.; Tardos, G.; Pfeffer, R. A microlevel-based characterization of granulation phenomena. Powder Technol. 1991, 65, 257-272. [CrossRef]

13. To, D.; Dave, R.N. Fluid bed film coating of fine ibuprofen particles. Powder Technol. 2016, 290, 102-113. [CrossRef]

14. Mawatari, Y.; Koide, T.; Tatemoto, Y.; Takeshita, T.; Noda, K. Comparison of three vibrational modes (twist, vertical and horizontal) for fluidization of fine particles. Adv. Powder Technol. 2001, 12, 157-168. [CrossRef]

15. Zhu, Q.; Li, H. Study on magnetic fluidization of group C powders. Powder Technol. 1996, 86, $179-185$.

16. Ichikawa, H.; Tokumitsu, H.; Jono, K.; HUKUDA, T.; Osako, Y.; Fukumori, Y. Coating of pharmaceutical powders by fluidized bed process, Part 6: Microencapsulation using blend and composite latex of copoly (ethyl acrylate-methyl methacrylate-2-hydroxyethyl methacrylate). Chem. Pharm. Bull. 1994, 42, 1308-1314. [CrossRef]

17. Watano, S.; Nakamura, H.; Hamada, K.; Wakamatsu, Y.; Tanabe, Y.; Dave, R.N.; Pfeffer, R. Fine particle coating by a novel rotating fluidized bed coater. Powder Technol. 2004, 141, 172-176. [CrossRef]

18. Chen, Y.; Jallo, L.; Quintanilla, M.A.; Dave, R.N. Characterization of particle and bulk level cohesion reduction of surface modified fine aluminum powders. Colloids Surf. A Physicochem. Eng. Asp. 2010, 361, 66-80. [CrossRef]

19. Chen, Y.; Yang, J.; Mujumdar, A.; Dave, R.N. Fluidized bed film coating of cohesive Geldart group C powders. Powder Technol. 2009, 189, 466-480. [CrossRef]

20. Hampel, N.; Roydeva, E.; Bück, A.; Tsotsas, E. Coating of finely dispersed particles by two-fluid nozzle. Particuology 2018, 38, 80-93. [CrossRef]

21. Mezhericher, M.; Ladizhensky, I.; Etlin, I. Atomization of liquids by disintegrating thin liquid films using gas jets. Int. J. Multiph. Flow 2017, 88, 99-115. [CrossRef]

22. Mezhericher, M.; Nunes, J.K.; Guzowski, J.J.; Stone, H.A. Aerosol-assisted synthesis of submicron particles at room temperature using ultra-fine liquid atomization. Chem. Eng. J. 2018, 346, 606-620. [CrossRef]

23. Mezhericher, M.; Rieck, C.; Razorenov, N.; Tsotsas, E. Ultrathin coating of particles in fluidized bed using submicron droplet aerosol. Particuology 2020. [CrossRef]

24. Lefebvre, A.H.; McDonell, V.G. Atomization and Sprays; CRC Press: Boca Raton, FL, USA, 2017.

25. Mezhericher, M.; Razorenov, N.; Mazor, G.; Ju, Y.; Stone, H.A. Submicron aerosols of liquid fuels: Method of production, experimental characterization and a semi-empirical model. Appl. Energy 2019, 235, 1651-1663. [CrossRef]

26. Sondej, F.; Bück, A.; Tsotsas, E. Comparative analysis of the coating thickness on single particles using X-ray micro-computed tomography and confocal laser-scanning microscopy. Powder Technol. 2016, 287, 330-340. [CrossRef]

27. Chen, Y.; Yang, J.; Dave, R.N.; Pfeffer, R. Fluidization of coated group C powders. AIChE J. 2008, 54, $104-121$. [CrossRef]

28. Dewettinck, K.; Huyghebaert, A. Top-spray fluidized bed coating: Effect of Process variables on coating efficiency. Lebensm. Wiss. Und Technol. 1998, 31, 568-575. [CrossRef]

29. Liu, L.X.; Litster, J.D. Spouted bed seed coating: The effect of process variables on maximum coating rate and elutriation. Powder Technol. 1993, 74, 215-230. [CrossRef]

30. Takei, N.; Unosawa, K.; Matsumoto, S. Effect of the spray-drying process on the properties of coated films in fluidized bed granular coaters. Adv. Powder Technol. 2002, 13, 333-342. [CrossRef]

31. Du, J.; Bück, A.; Tsotsas, E. Influence of process variables on spray agglomeration process in a continuously operated horizontal fluidized bed. Powder Technol. 2020, 363, 195-206. [CrossRef]

32. Jiang, Z.; Bück, A.; Tsotsas, E. CFD-DEM study of residence time, droplet deposition, and collision velocity for a binary particle mixture in a Wurster fluidized bed coater. Dry. Technol. 2018, 36, 638-650. [CrossRef]

Publisher's Note: MDPI stays neutral with regard to jurisdictional claims in published maps and institutional affiliations. 